\title{
$\$$ Research Square

\section{Role of Preoperative Pregabalin in Reducing Inhalational Anaesthetic Requirements in Abdominal Hysterectomy: Randomized Controlled Trial}

Ahmed Abdalla Mohamed ( $\square$ ahmed.aboali7268@gmail.com )

Cairo University Faculty of Medicine https://orcid.org/0000-0002-3024-7974

Gehan Helmy Ibrahim

Cairo University Faculty of Medicine

Nesrine Abd Elrahman El Refai

Cairo University Faculty of Medicine

Tamer Mousaad Abdelhamid Gamaleldin

Cairo University Faculty of Medicine

Reham Ali Abdelrahman Abdelrahman

Cairo University Faculty of Medicine

Nasser Mohamed Dobal

Cairo University Faculty of Medicine

Ehab Mohi Atta

Cairo University Faculty of Medicine

Norhan Abdelaleem Ali

Cairo University Faculty of Medicine

Tamer Mohamed Khair

Cairo University Faculty of Medicine

Safinaz Hassan Osman

Cairo University Faculty of Medicine

Mohamed Ibrahim Belita

Cairo University Faculty of Medicine

Ahmed A Seleem

Cairo University Faculty of Medicine

Maha Youssef Ismail

Cairo University Faculty of Medicine

Rania Samir Fahmy

Cairo University Faculty of Medicine

Ahmed Essam Salem

Cairo University Faculty of Medicine

Dr.Hany Mohamed El Hady

Cairo University Faculty of Medicine

Ahmed Mohamed Elbadawy

Cairo University Faculty of Medicine

Tahani Farrag 


\section{Research Article}

Keywords: Gabapentinoids, Pregabalin; Inhalation Anaesthetics, Isoflurane; Monitoring, Bispectral Index; Surgery, Abdominal Hysterectomy

Posted Date: January 8th, 2019

DOI: https://doi.org/10.21203/rs.2.183/v1

License: (c) (i) This work is licensed under a Creative Commons Attribution 4.0 International License. Read Full License 


\section{Abstract}

Background: preoperative oral pregabalin controls postoperative pain \& decreases anesthetic requirements in total intravenous anaesthesia. In this study, we hypothesized that preoperative pregabalin reduces inhaled isoflurane requirements.

Methods: Study was conducted in a university hospital, included 50 women (18-60 yrs.), ASA I or II, admitted to undergo elective abdominal hysterectomy under general anaesthesia. Time of study: June to September 2017. Exclusion criteria were allergy or hypersensitivity to pregabalin; patients on calcium channel blockers, antiepileptic drugs, antidepression drugs, any analgesics or sedatives, or oral hypoglycemic agents; and patients with severe cardiovascular, renal, hepatic or neurological dysfunction. Interventions: giving either oral pregabalin 150 mg or placebo to patients of both groups. Primary outcome measures: inhaled isoflurane requirements to maintain haemodynamics $\pm 20 \%$ of baseline\& bispectral index (BIS) of $40-60$, measured using MAQUET Flow-I anaesthetic machine. Secondary outcomes : attenuation of pressor response to intubation, postoperative pain, first time for rescue analgesia, total anaglesics and adverse effects.

Results: Isoflurane consumption was significantly less in pregabalin group $(7.80 \pm 1.27 \mathrm{ml} \mathrm{h}-1)$ versus $(12.27 \pm 2.49$ $\mathrm{ml} \mathrm{h}-1)$ in control group, $(\mathrm{P}=0.00)$. Better haemodynamic stability was in pregabalin group after intubation. First postoperative hour :the mean VAS score was significantly higher in control group (7.10 \pm 1.20$)$ compared to pregabalin group $(4.50 \pm 1.70), P<0.001$. All patients in control group received pethidine intramuscular. More patients in pregabalin group suffered dizziness.

Conclusion: preoperative pregabalin $150 \mathrm{mg}, 1 \mathrm{~h}$ before total abdominal hysterectomy has an inhaled anaestheticsparing effect, maintain haemodynamics and optimizes postoperative analgesia.

Keywords: Gabapentinoids, Pregabalin; Inhalation Anaesthetics, Isoflurane; Monitoring, Bispectral Index; Surgery, Abdominal Hysterectomy

Objectives: We aimed to investigate the effectiveness and safety of preoperative oral pregabalin 150 mg in women undergoing elective total abdominal hysterectomy under general anaesthesia.

Design: A prospective, randomized, double-blind, controlled study.

Trial Registry Number: ClinicalTrials.gov: NCT 03302208

\section{Background}

Balanced anaesthesia provides perioperative analgesia and improves haemodynamics by minimizing the inhalation concentration of volatile anesthetics. Inhalation an aesthetics inhibit excitatory neurotransmitters through direct presynaptic mechanisms. Isoflurane is a potent inhibitor of glutamate release, the principle excitatory neurotransmitter in the central nervous system, as well as inhibiting the release of norepinephrine, dopamine, and acetylcholine $\left({ }^{1,2}\right.$.)

Pregabalin is structural analog of the inhibitory neurotransmitter gamma aminobutyric acid (GABA), but it is not functionally related to it. Similar to its predecessor, gabapentin, it binds with high affinity to $\left(a_{2} \delta\right)$ subunit of the presynaptic voltage-gated calcium channels reducing the release of calcium and subsequently inhibiting the release of excitatory neurotransmitters including glutamate, norepinephrine, substance $P$ and clacitonin gene related peptide thus increasing neuronal GABA level (3) and thereby preventing hyperalgesia and central sensitization. (4) 
Pregabalin plays an established role in the management of neuropathic pain and other chronic pain neuralgia.(5) Pregablin has antiepileptic, analgesic, anxiolytic and sleep modulating activities (6). Preoperative pregabalin has been used in various doses and surgeries as a non-opioid

adjuvant to control postoperative pain and limit reliance on opioid analgesia(7-10)

Recently, administration of preoperative pregabalin in intravenous sedation (11)and total intravenous anaesthesia (12) has decreased propofol dose needed to maintain adequate sedative and anaesthetic levels.

Up to date, the effect of preoperative pregabalin on inhaled anaesthetic depth is unknown.

The primary outcome of this study was inhaled isoflurane requirements $\left(\mathrm{ml} \mathrm{h}^{-1}\right)$, needed to maintain intraoperative haemodynamic stability $\pm 20 \%$ of baseline and bispectral index (BIS) value between $40-60$ which was mearsured using MAQUET flow-I anaesthetic machine. Secondary outcomes included attenuation of pressor response to intubation and extubation; pain intensity postoperatively, first time to rescue analgesia and total pethidine consumption; and the incidence of adverse effects related to pregabalin including sedation, headache, blurred vision, dizziness, nausea and vomiting for $6 \mathrm{~h}$ postoperatively.

\section{Methods}

This prospective, parallel, randomized, double-blind, placebo-controlled clinical study was performed in Cairo University Hospital, Department of Anaesthesia, Intensive Care and Pain Management, Faculty of Medicine, Cairo University, Egypt.

This study was approved by the institutional review board of Cairo University -Kasr Alainy (Research Ethics Committee with Approval Number: N- 67-2017

. The study was registered at ClinicalTrails.gov (NCT 03302208). Written informed consent was obtained from each patient.

Patients were enrolled from June to September 2017. Eligible participants were ASA physical status I or II women, aged between 18 and 60 years, who were admitted for elective total abdominal hysterectomy surgery under general anaesthesia. Exclusion criteria were allergy or hypersensitivity to pregabalin; patients on calcium channel blockers, antiepileptic drugs, antidepression drugs, any analgesics or sedatives, or oral hypoglycemic agents; and patients with severe cardiovascular, renal, hepatic or neurological dysfunction. Fifty patients were randomly assigned to one of two groups by using a computer-generated random number table (CONSORT flow chart shown in Figure1 ). The control group (group $\mathrm{C}, \mathrm{n}=25$ ) received oral placebo capsules containing fine sugar, pregabalin group ( $g r o u p ~ P, n=25$ ) received oral pregabalin $150 \mathrm{mg}$ (Lyrica ${ }^{\mathrm{TM}}$, Pfizer Inc.) at $1 \mathrm{~h}$ before the anticipated time of the anaesthetic induction. The placebo and pregabalin were provided in white capsule by a pharmacist who was not otherwise involved in this study. The capsules were further packed in opaque plastic containers labeled with the randomization number. The medication was administered by anesthesiologists who also performed the subsequent assessments.

Anesthesiologists and patients were not aware of the content of the capsules. The randomization was not revealed to the investigators before all measurements were conducted and entered into the database.

The night before surgery, preoperative assessment was done and all patients were instructed on visual analog scale (VAS 0-10 cm) for assessment of pain (VAS 0= no pain, VAS 10= unbearable pain). Following $8 \mathrm{~h}$ period of fasting, the patients attended at the preanaesthetic room where baseline haemodynamic measurements; systolic (SBP), 
diastolic (DBP), mean blood pressure (MBP) and heart rate (HR) were determined from the mean of three readings that fell within $10 \%$ of each other, taken at least one minute apart. Intravenous access was established with an 18gauge peripheral intravenous catheter and all patients received ranitidine $50 \mathrm{mg}$ iv and metoclopramide $10 \mathrm{mg}$ iv. Patients were transferred to the operating room where standard monitoring including electrocardiography (ECG), pulse oximetry $\left(\mathrm{SpO}_{2}\right)$, non-invasive blood pressure monitoring and Bi-Spectral Index monitor (Aspect Medical Systems Inc. Leiden, The Netherlands) were applied.

A standardized anaesthesia protocol was followed. General anaesthesia was induced with thiopental sodium 5-7 mg $\mathrm{kg}^{-1} \mathrm{iv}$, fentanyl $1 \mu \mathrm{g} \mathrm{kg}^{-1}$ iv and atracurium $0.5 \mathrm{mg} \mathrm{kg}^{-1}$ iv. Laryngoscopy and intubation were done after 3 minutes. Patients' lungs were mechanically ventilated, using MAQUET Flow-I anaesthetic machine (Model No. USE1903A. GE Medical Systems Information Technologies, Inc., Freiburg, Germany), at tidal volume of 6-8 $\mathrm{ml} \mathrm{kg}^{-1}$, inspired oxygen fraction $\left(\mathrm{FIO}_{2}\right)$ of 0.6 and the respiratory rate was adjusted to maintain normocapnia (end-tidal $\mathrm{CO}_{2}$ between 34-38 $\mathrm{mmHg}$ ). All patients received lactate ringer solution iv based on calculated preoperative deficit and estimated intraoperative blood loss. Isoflurane concentration was adjusted to maintain intraoperative haemodynamics stability (blood pressure and heart rate $\pm 20 \%$ of baseline and BIS value in the range of $40-60$ ). SBP, DBP, MBP and HR were recorded immediately after anaesthetic induction, after intubation and after 3 minutes, 5 minutes, 10 minutes and every 15 minutes until extubation. Haemodynamics parameters out of range $\pm 20 \%$ of baseline values in the presence of normocapnia were managed by incremental increase or decrease of isoflurane till haemodynamics normalization.

If no response after 10 minutes, additional doses of fentanyl $0.5 \mu \mathrm{g} \mathrm{kg}^{-1}$ were given. At the end of surgery, anaesthesia was discontinued, surgical time was checked and recorded and residual muscle relaxant effects were reversed with neostigmine $0.04-0.08 \mathrm{mg} \mathrm{kg}^{-1}$ iv and atropine $0.01-0.02 \mathrm{mg} \mathrm{kg}^{-1} \mathrm{iv}$. Intraoperative isoflurane requirement was calculated as a mean value $\left(\mathrm{ml} \mathrm{h}^{-1}\right)$ by dividing the total consumption $(\mathrm{ml})$, measured using MAQUET Flow-I anaesthetic machine, by the duration of surgery $(h)$ to correct for the variable duration of surgery.

Postoperatively, haemodynamics measurements were recorded immediately after extubation, at 3 minutes and 10 minutes. Postoperative pain was assessed using VAS and pethidine $1 \mathrm{mg} \mathrm{kg}^{-1} \mathrm{im}$ was given as rescue analgesic for postoperative pain if VAS score $\geq 6$. The time to requirement of first rescue analgesic and total pethidine consumption in $6 \mathrm{~h}$ postoperative were recorded. Postoperative nausea, vomiting, headache, dizziness, blurred vision and sedation which might occur as side effects of pregabalin were evaluated at 1, 2, 4 and $6 \mathrm{~h}$ postoperatively. Over sedation was defined as a score $\leq 2$ on a 5-point scale (13). Score 1 (barely arousable): Asleep, needs shaking or shouting to arise. Score 2 (asleep): Eyes closed, arousable with soft voice or light touch. Score 3 (sleepy): Eyes opened, less active, and responsive. Score 4: Awake. Score 5: Agitated.

\section{Sample Size}

The number of patients required for the statistical analysis to identify a clinical relevant effect of oral pregabalin on the primary endpoint; inhalation anaesthetic requirement (inhaled isoflurane requirement) was calculated using Student's t-test. Taking a power of the study of $80 \%$ and alpha error of 0.05 , based on a previous study that showed preoperative pregabalin versus placebo reduced intraoperative inhalational anaesthesia (sevoflurane \%) by 0.9 versus 1.2 with standard deviation $(S D \pm 0.31)^{13}$, a minimum number of 20 patients were needed for each group. This number was increased to 25 patients per group to compensate for possible dropout.

\section{Statistical analysis}

Data were statistically described in terms of mean \pm standard deviation $( \pm S D$ ), and range, or frequencies (number of cases) and percentages when appropriate. Comparison of numerical variables between the study groups was done 
using the Student t-test for independent samples. For comparing categorical data, Chi-square (C2) test was performed. Exact test was used instead when the expected frequency was less than 5 . P values less than 0.05 were considered statistically significant. All statistical calculations were done using computer program IBM SPSS Statistics 22 (IBM Corp., Armonk, NY, USA).

Trial Registry Number: ClinicalTrails.gov:NCT 03302208

\section{Results}

Of 137 women who were assessed for eligibility, 50 patients completed the study as planned without dropouts (CONSORT Flow Chart, Figure 1). Patients' characteristics were comparable in both groups. There were no statistically significant differences between the two groups regarding age, weight, height and ASA physical status (Table 1).

The mean surgical time was significantly less in pregabalin group ( $1.47 \pm 0.47 \mathrm{~h}$ ) compared to control group, where the mean surgical time was $(2.04 \pm 0.48 \mathrm{~h})(\mathrm{P}$ value= 0.00$)$.

Isoflurane requirements was calculated as a mean value $\left(\mathrm{ml} \mathrm{h}^{-1}\right)$ by dividing the total consumption ( $\left.\mathrm{ml}\right)$ of each patient by the duration of surgery $(\mathrm{h})$. Pregabalin group consumed significantly less isoflurane during surgery $7.80 \pm$ $1.27 \mathrm{ml} \mathrm{h}^{-1}$ compared to control group which consumed $12.27 \pm 2.49 \mathrm{ml} \mathrm{h}^{-1}, \mathrm{P}=0.00$.

The total volume of isoflurane consumed by each patient throughout surgery in pregabalin group and control group is shown in Figure 2.

The baseline haemodynamics parameters were similar in both groups. Better intraoperative haemodynamics stability was observed in pregabalin group compared to control group. In the control group, the HR was significantly higher during the first 75 min of surgery and after extubation at 3 and 10 min compared to pregabalin group (Table 2). SBP was comparable in the two groups preoperatively, at induction and at intubation, then it was significantly higher in the control group at $5 \mathrm{~min}$ after intubation, all through the surgery; and $3 \mathrm{~min}$ and $10 \mathrm{~min}$ after extubation compared to pregabalin group (Table 3). DBP was significantly higher in the control group compared to pregabalin group at 5, 10, $30,45,60,75,90$ min after intubation; and 3 and 10 min after extubation (Table 3 ). In Control group, MBP was significantly higher compared to pregabalin group at 5 min after induction, throughout surgery; and at 3 and 10 min after extubation (Table 3).

Within the first hour, the mean VAS score in patients in the control group was significantly higher $(7.1 \pm 1.2)$ compared to those in pregabalin group $(4.5 \pm 1.7),(\mathrm{P}<0.001)$ and all patients in control group (25 patients) required postoperative pethidine IM $(66.00 \pm 23.81 \mathrm{mg})$. Only two patients in pregabalin group needed pethidine IM, one received $75 \mathrm{mg}$ after 2 hours and the other received $50 \mathrm{mg}$ after 4 hours, postoperatively. The incidence of side effects, postoperatively, were comparable in both groups (nausea, vomiting, headache and blurred vision), however 15 patients $(60 \%)$ in the pregabalin group experienced dizziness compared to only 2 patients (8\%) in the control group $(\mathrm{P}<0.001)$ (Table 4). Postoperatively, patients in pregabalin group were less apprehensive and well sedated compared to those in the control group, who were awake and agitated (Table 4).

\section{Discussion}

In this study, a single dose of oral pregabalin $150 \mathrm{mg} 1 \mathrm{~h}$ prior to anaesthetic induction reduced intraoperative inhaled isoflurane requirement $(\approx 36.4 \%)$ needed to achieve adequate level of anaesthesia while maintaining haemodynamic stability in ASA I and II women undergoing elective total abdominal hysterectomy under general anaesthesia. 
To the best of our knowledge isoflurane-sparing effect of preemptive pregabalin has not been demonstrated in previous studies. Recently, Gupta and Colleagues compared the effect of two doses of pregabalin premedication (75 mg night before surgery and either $150 \mathrm{mg}$ or $300 \mathrm{mg} 1$ hour before surgery) with diazepam (10 mg night before surgery and $5 \mathrm{mg}$ one hour before surgery) on perioperative anaesthetic and analgesic requirements during laparoscopic cholecystectomy. They demonstrated that pregabalin reduced the consumption of thiopentone, fentanyl and sevoflurane without significant differences between the two doses. They used sevoflurane concentration (\%) which was needed constantly for more than $50 \%$ duration of surgery. Sevoflurane \% was $1.20 \pm 0.30$ in diazepam group, $0.93 \pm 0.25$ in pregabalin $150 \mathrm{mg}$ group and $1.00 \pm 0.00$ in pregabalin $300 \mathrm{mg}$ group.(13)

In our study, the actual total volume of isoflurane consumed by each patient was measured using MAQUET Flow-1 anaesthetic machine and was used to calculate the mean isoflurane requirement. Pregabalin group consumed $7.80 \pm$ $1.27 \mathrm{ml} \mathrm{h}^{-1}$ while, the control group consumed $12.27 \pm 2.49 \mathrm{ml} \mathrm{h}^{-1}$. In addition, BIS value was recorded throughout surgery and maintained in the range of 40-60 to ensure adequate level of anaesthesia.

Preliminary investigation of preoperative pregabalin in total intravenous anaesthesia patients reported a decreased anaesthetic requirement (required propofol and remifentanil doses) to obtain bispectral index value less than 60 . Total amount of propofol was lower after premedication with pregabalin $300 \mathrm{mg}$ compared to that after pregabalin $150 \mathrm{mg} \cdot{ }^{(12)}$.Similarly, in intravenous sedation oral premedication with pregabalin (100 and $200 \mathrm{mg}$ ) reduced the amount required to obtain an acceptable and adequate sedation level (11)

The mechanism by which pregabalin has an anaesthetic-sparing effect has not been previously studied. The regulation of neurotransmitter release from presynaptic nerve terminals may be related to anaesthetic action in the central nervous system (12) Pregabalin inhibits the release of excitatory neurotransmitters from presynaptic terminals (3); therefore, it is probably reasonable that pregabalin affects anaesthetic action (13).

In this study, oral pregabalin $150 \mathrm{mg}$ given an hour prior to anaesthetic induction was fruitful at producing anaesthetic sparing effect, as pregabalin demostrates highly predictable and linear pharmacokinetics. Absorption is extensive and rapid with maximum plasma concentrations attained within one hour and absolute bioavailability of approximately $90 \%$ irrespective of the dosage .

Single dose of oral pregabalin $150 \mathrm{mg}$ was chosen, as it has been proven to be an optimal dose for postoperative pain management $(1,15,16)$. Mishriky and colleagues reported in a systematic review that a single preoperative dose was as effective as multiple doses and all doses of pregabalin (75,100,150 and 300) resulted in opioid sparing effect. However, smaller doses (75,100 mg) were less effective and higher doses (300 mg) were limited by adverse effect; mainly dizziness and somnolence (7)

Similar to that reported in previous studies in various patient populations undergoing different surgeries $(17,18,19)$ pregabalin premedication resulted in intraoperative haemodynamic stability with suppression of the reflex tachycardia and hypertension related to intubation and extubation. The mechanism by which pregabalin attenuates haemodynamic pressor response to laryngoscopy and intubation is unknown, however, as a calcium channel modulator ${ }^{(3)}$ it may be attributed to inhibition of calcium efflux from muscle cells (20)

Pregabalin as a preventive analgesic that attenuates neuronal hyperexcitability and central sensitization (4) resulted in a remarkable pain relief with reduction of narcotic requirement in the immediate postoperative period. This goes in accordance with plenty of studies that proved pregabalin's antinociceptive action in relieving postoperative pain (7-10, 21-27). In addition, it prolonged the duration for first rescue analgesia up to $6 \mathrm{~h}$ postoperatively. Prolongation of 
postoperative analgesia has been previously described $(21,22,26,27)$. This favorable effect may be attributable to pregabalin's long elimination half-life (ranging from 5.5 to 6.7 h) (14)

A single dose of pregabalin $150 \mathrm{mg}$ was generally well tolerated with limited side effects. The most commonly encountered side effects after pregabalin administration were dizziness and somnolence. Fifteen patients suffered from postoperative dizziness in the pregabalin group while only two patients had dizziness in the control group, this goes in accordance with results of previous studies $(10,21,25,26,27)$

In the present study, though the incidence of postoperative nausea and vomiting (PONV) was less in patients premedicated with pregabalin ( $20 \%$ and $8 \%$ respectively) compared to patients in the control group ( $44 \%$ and $20 \%$ respectively), the difference did not reach statistical significance. This result is consistent with that of some studies $(17,21,25)$.The potential antiemetic effect of pregabalin is not shown in our study as the incidence of PONV was a secondary endpoint; a larger study may be needed. However, other studies have verified the effectiveness of pregabalin in reducing PONV and rescue antiemetics in patients undergoing abdominal hysterectomy ${ }^{(28)}$ and various other surgeries (29). Gabapentinoids may preempt PONV directly through inhibition in the area postrema, mitigation of tachykinin neurotransmission and reduction in postoperative inflammation (30), or indirectly as a product of perioperative opioid-sparing effect.(7)

The sedation observed in patients receiving pregabalin was modest and clinically acceptable. In intravenous sedation, pregabalin augments the sedative effect of propofol $(11,33)$. In some studies pregabalin has been used as preoperative premedication to increase perioperative sedation $(31,32)$, while others reported the increased sedation level after pregabalin administration as a side effect

These results are promising. However, this study is limited by its sample size and the homogeneity of the patient population. Further large studies in different patient populations are needed to verify the anaesthetic-sparing effect of pregabalin and its long term beneficial sequelae.

\section{Conclusion}

A single administration of pregabalin $150 \mathrm{mg}$, one hour before elective total abdominal hysterectomy, was effective at reducing intraoperative isoflurane requirement, attenuating haemodynamic response to laryngoscopy, endotracheal intubation and extubation, as well as optimizing the quality and duration of postoperative analgesia without clinically serious adverse effects. Thus, pregabalin may be a useful adjuvant to general anaesthesia in selected patients.

\section{Declarations}

\section{Declarations}

Ethics: This study was approved by the institutional review board of Cairo University -Kasr Al Ainy (Research Ethics Committee).

Approval Number: N-67-2017

Date of approval: 21/10/2017

Board Name: Research Ethics Committee

Board Affiliation: Faculty of Medicine, Cairo University

Page $8 / 17$ 
Phone: +201003657120 Email: kasralainirec@gmail.com

Address: Cairo University, faculty of Medicine

Chairman of the Research Ethic Committee-Cairo University: M. Mohsen Ibrahim, M.B., B.CH., M.D. Fax no. 279488 79 e-mail:mibrahim_02@yahoo.com

Trial Registry Number: ClinicalTrials.gov: NCT 03302208

Consent for publication: Not applicable.

Availability of data and materials: The data that support the findings of this study are available from Cairo university hospitals, but restrictions apply to the availability of these data, which were used under license for the current study, and so are not publicly available. Data are however available from the authors upon reasonable request and with permission of Cairo university hospitals.

Competing interests

The authors declare that they have no competing interests.

Financial support and sponsorship: none.

Authors' contributions:

AAM designed the study, acquired and analyzed data and prepared the manuscript.

GHI designed the study, acquired and analyzed data and prepared the manuscript.

NAE, NMD, AME.HHZ, AAS, MYI and MIB designed the study, analyzed data and prepared the manuscript.

TMA RAA, HME and TFA helped conduct the study, acquired data and drafted the manuscript.

All authors reviewed and approved the final manuscript.

Acknowledgments: We thank the preoperative and operating room staff at Obstetrics and Gynecology, Cairo University Hospital for their assistance with the study.

2. Financial support and sponsorship: All instruments \& drugs used in the study were covered from the Anesthesia department resources.

Sponsorship: None

3. Presentation (for original articles only): None

Author details

1-Department of Anaesthesia and Critical Care Medicine, Cairo University, Cairo, EGYPT

2- Department of Anaesthesia and Critical Care Medicine, Faculty of Medicine,

\section{References}


1- Westphalen RI. , Desai KM. and Hemmings HC Jr. Presynaptic inhibition of the release of multiple major central nervous system neurotransmitter types by the inhaled anaesthetic isoflurane. Br J Anaesth 2013; 110:592-9.

2- Baumgart J P., Zhou ZY., Hara M., Cook DC. , Hoppa MB. and Ryan TA.et al. Isoflurane inhibits synaptic vesicle exocytosis through reduced $\mathrm{Ca}^{2+}$ influx, not $\mathrm{Ca}^{2+}$ - exocytosis coupling. Proc Natl Acad Sci USA 2015; 112:11959-64.

3- Bauer CS., Rahman W., Tran-van-Minh A., Lujan R., Dickenson AH. and Dolphin AC. The anti-anti-allodynic alpha (2)delta ligand pregabalin inhibits the trafficking of the calcium channel alpha (2) delta-1 subunit to presynaptic terminals in vivo. Biochem Soc Trans. 2010; 38:525-8.

4- Bannister K., Sikandar S., Bauer CS., Dolphin AC., Porreca F. and Dickenson AH. Pregabalin supresses spinal neuronal hyperexcitability and visceral hypersensitivity in the absence of peripheral pathophysiology. Anaesthesiology 2011; 115: 144-52.

5- Baidya DK., Agarwal A., Khanna P. and Arora MK. Pregabalin in acute and chronic pain. J Anaesthesiol Clin Pharmacol. 2011; 27: 307-14.

6-Tassone DM., Boyce E., Guyer J. and Nuzum D. Pregabalin: a novel gamma-aminobutyric acid analogue in the treatment of neuropathic pain, partial-onset seizures, and anxiety disorders. Clin Ther. 2007; 29:26-48.

7- Mishriky BM., Waldron NH. and Habib AS. Impact of pregabalin on acute and persistent postoperative pain: a systemic review and meta-analysis. Br J Anaesth 2015; 114: 10-31.

8-Asgari Z., Rouholamin S., Nataj M., Sepidarkish M., Hosseini R. and Razavi M. Dose ranging effects of pregabalin on pain in the patients undergoing laparoscopic hysterectomy: A randomized, double-blind, placebo-controlled, clinical trial. J Clin Anesth 2017; 38: 13-7.

9- Jiang HL., Huang S., Song J., Wang X. and Cao ZS. Preoperative use of pregabalin for acute pain in spine surgery: A meta-analysis of randomized controlled trails. Medicine (Baltimore) 2017; 96:e6129.

10- Li F., Ma J., Kuang M., Jiang X., Wang Y. and Lu B. et al. The efficacy of pregabalin for the management of postoperative pain in primary total knee and hip arthroplasty: a meta-analysis. J Orthop Surg Res 2017; $12: 49$.

11-Karube N., Ito S., Sako S., Hirokawa J. and Yokoyama T. Sedative effects of oral pregabalin premedication on intravenous sedation using propofol target-controlled infusion. J Anaesth 2017; 31: 586-92.

12-Chavush MA., Yagar S., Erturk A. and Ozgok A. Preliminary investigation of preoperative pregabalin and total intravenous anesthesia doses: a randomized controlled trial. J Clin Anesth 2017; 41:137-40.

13-Gupta P., Saxena A. and Chaudhary L. Effect of pregabalin premedication on the requirement of anaesthetic and analgesic drugs in laparoscopic cholecystectomy: Randomized comparison of two doses. Anesth Essays Res. 2017; 11:330-3.

14- Bockbrader HN. , Radulovic LL., Posvar EL., Strand J C. , Avey C W. and Busch J. et al. Clinical pharmacokinetics of pregabalin in healthy volunteers. J Clin Pharmacol. 2010; 50: 941-50.

15- Hetta DF., Mohamed MA. and Mohammad MF. Analgesic efficacy of pregabalin in acute postmastectomy pain: placebo controlled dose ranging study. J Clin Anesth 2016; 34: 303-9. 
16- Fujita N., Tobe M., Tsukamoto N., Saito S. and Obata H.A randomized placebo-controlled study of preoperative pregabalin for postoperative anaglesia in patients with spinal surgery. J Clin Anesth 2016; 31: 149-53.

17-Sundar AS., Kodali R., Sulaiman S., Ravullapali H., Karthekeyan R. and Vakamudi M. The effects of preemptive pregabalin on attenuation of stress response to endotracheal intubation and opioid-sparing effect in patients undergoing off-pump coronary artery bypass grafting. Ann Card Anaesth 2012; 15:18-25.

18- Gupta K., Bansal P., Gupta PK. and Singh YP. Pregabalin premedication- a new treatment option for haemodynamic stability during general anaesthesia: a prospective study. Anesth Essays Res 2011; 5:57-62

19-Bhawna R., Gupta K., Gupta PK., Agarwal S., Jain M. and Chauhan H. Oral pregabalin premedication for attenuation of haemodynamic pressor response of airway instrumentation during general anaesthesia:a dose response study. Indian J Anaesth 2012; 56:49-54.

20-Memis D., Turan A., Karamanlioglu B., Seker S. and Ture M. Gabapentin reduces cardiovascular responses to laryngoscopy and tracheal intubation. Eur J Anaesthesiol 2006; 23:686-90.

21-Kohli M., Murali T., Gupta R., Khan P. and Bogra J. Optimization of subarachnoid block by oral pregabalin for hysterectomy. J Anaesthesiol Clin Pharmacol 2011;27:101-5.

22-Steinberg AC., Schimpf MO., White AB., Mathew C., Ellington D R. and Jeppson P. et al. Preemptive analgesia for postoperative hysterectomy pain control: systemic review and clinical practice guidelines. Am J Obstet Gynecol 2017; 217:303-13.

23-Kim JC., Byun S., Kim S., Lee SY., Lee JH. And Ahn S. Effect of preoperative pregabalin as an adjunct to a multimodal analgesic regimen in video-assisted thoracoscopic surgery: A randomized controlled trial. Medicine (Baltimore) 2017; 96: e8644.

24- Ahn S., Byun SH., Park K., Ha JL., Kwon B. and Kim JC. Analgesic efficacy of preemptive pregabalin administration in arthroscopic shoulder surgery: a randomized controlled trial. Can J Anesth. 2016; 63: 283-9.

25-Yucel A., Ozturk E., Aydoan MS., Durmus M., Colak C. and Ersoy MO. Effects of 2 different doses of pregabalin on morphine consumption and pain after abdominal hysterectomy: a randomized, double-blind clinical trial. Curr Ther Res Clin Exp.

2011; 72: 173-83.

26-Rajappa GC., Vig S., Bevanaguddaiah Y. and Anadaswamy TC. Efficacy of pregabalin as premedication for postoperative analgesia in vaginal hysterectomy. Anesth Pain Med. 2016; 6: e34591.

27- Raj PG. and Amingad B. Efficacy of preemptive oral pregabalin for prolonging post-operative analgesia in modified radical mastectomies. Indian J Clin Anaesth. 2016; 3: 374-9.

28- Wang Y., Xia M., Shan N., Yuan P., Wang D. and Shao J. et al. Pregabalin can decrease acute pain and postoperative nausea and vomiting in hysterectomy: A meta-analysis. Medicine 2017; 96:e7714.

29- Grant M C., Betz M., Hulse M., Zorrilla-Vaca A., Hobson D. and Wick E. et al. The effect of preoperative pregabalin on postoperative nausea and vomiting: a meta-analysis. Anesth Analg 2016; 123: 1100-7. 
30-Fehrenbacher JC., Taylor CP. And Vasko MR. Pregabalin and gabapentin reduce release of substance P and CGRP from rat spinal tissues only after inflammation or activation of protein kinase C. Pain 2003;105:133-41.

31- Ghai A., Gupta M., Rana N. and Wadhera R. The effect of pregabalin and gabapentin on preoperative anxiety and sedation: a double blind study. Anesth Analg. 2009;108:1140-5.

32- White PF., Tufanogullari B., Taylor J. and Klein K. The effect of pregabalin on preoperative anxiety and sedation levels: a dose-ranging study. Anesth Analg.2009; 108: 1140-5.

33- Yosry M., Shafi ME. and Othman IS. Premedication with oral pregabalin $150 \mathrm{mg}$ reduces propofol sedation during retro bulbar anesthesia for vetrectomy surgery. Eur J Anaesth. 2008; 25: 132-3.

\section{Tables}

Table (1): Patients' characteristics and surgical time in pregabalin group (Group P) and control group (Group C).

Data are presented as mean \pm SD or number and percentage (\%)

\begin{tabular}{lccc}
\hline & Pregabalin Group & Control Group & P value \\
& $(\mathrm{n}=25)$ & $(\mathrm{n}=25)$ & \\
\hline Age (year) & $49.10 \pm 4.80$ & $47.10 \pm 5.0$ & 0.15 \\
Weight $(\mathrm{kg})$ & $74.33 \pm 9.53$ & $73.32 \pm 9.52$ & 0.82 \\
Height $(\mathrm{cm})$ & $166.32 \pm 7.20$ & $165.41 \pm 7.70$ & 0.61 \\
ASA (I/II) & $11 / 14(44 / 56 \%)$ & $8 / 17(32 / 68 \%)$ & 0.38 \\
Surgical time (h) & $1.47 \pm 0.47$ & $2.04 \pm 0.48$ & $0.000 *$ \\
& & & \\
\hline
\end{tabular}

$* \mathrm{P}<0.05$ is considered statistically significant.

Table (2): Heart rate (HR) in pregabalin group (Group P) and control group (Group C).

Data are presented as mean $\pm \mathrm{SD}$. 


\begin{tabular}{lccc}
\hline \multicolumn{1}{c}{ HR (b/m) } & $\begin{array}{c}\text { Pregabalin Group } \\
(\mathbf{n}=\mathbf{2 5})\end{array}$ & $\begin{array}{c}\text { Control } \\
\text { Group } \\
(\mathbf{n}=\mathbf{2 5})\end{array}$ & P value \\
& $86.0 \pm 11.7$ & $81.5 \pm 11.4$ & 0.17 \\
\hline Pre-operative & $73.9 \pm 7.5$ & $79.6 \pm 9.5$ & $0.022^{*}$ \\
Induction & $67.0 \pm 9.4$ & $78.0 \pm 10.4$ & $<0.001^{*}$ \\
Intubation & $70.0 \pm 7.5$ & $78.2 \pm 8.7$ & $0.001^{*}$ \\
3 min after intubation & $68.6 \pm 5.4$ & $77.3 \pm 8.8$ & $>0.001^{*}$ \\
5 min after intubation & $69.9 \pm 5$ & $75.2 \pm 11.8$ & $0.044^{*}$ \\
10 min after intubation & $68.2 \pm 4.4$ & $74.6 \pm 10.2$ & $0.006^{*}$ \\
15 min after intubation & $64.7 \pm 5.2$ & $74.6 \pm 12$ & $<0.001^{*}$ \\
30 min after intubation & $66.4 \pm 2.7$ & $77.1 \pm 7.9$ & $<0.001^{*}$ \\
45 min after intubation & $65.8 \pm 5.2$ & $75.0 \pm 8.9$ & $<0.001^{*}$ \\
60 min after intubation & $66.5 \pm 5.5$ & $75.7 \pm 11.1$ & $0.001^{*}$ \\
75 min after intubation & $69.1 \pm 6.7$ & $76.0 \pm 13.7$ & 0.057 \\
90 min after intubation & $70.4 \pm 7.4$ & $76.8 \pm 11$ & 0.09 \\
105min after intubation & $69.7 \pm 8.4$ & $74.1 \pm 11.5$ & 0.385 \\
120min after intubation & $67.3 \pm 5.7$ & $77.1 \pm 7.9$ & 0.059 \\
135min after intubation & $68.0 \pm 12.7$ & $79.1 \pm 9.3$ & 0.152 \\
150min after intubation & $82.3 \pm 5.8$ & $92.2 \pm 7.8$ & $<0.001^{*}$ \\
3 min after extubation & $76.9 \pm 4.7$ & $87.4 \pm 9.8$ & $<0.001^{*}$ \\
\hline 10 min after extubation & & & \\
\hline & & & \\
& & &
\end{tabular}

$\mathrm{P}^{*}>0.05$ is considered statistically significant.

Table (3): Systolic blood pressure (SBP), Diastolic blood pressure (DBP) and Mean blood pressure (MBP) in Pregabalin Grour and Control Group (Group C). Data are presented as mean \pm SD. 


\begin{tabular}{|c|c|c|c|c|c|c|c|c|c|c|c|c|}
\hline & $\begin{array}{l}\text { Group } \\
(n=25)\end{array}$ & $P$ & $\begin{array}{l}\text { Group } \\
(n=25)\end{array}$ & $\mathrm{C}$ & $P$ value & $\begin{array}{ll}\text { Group } \\
(n=25)\end{array}$ & $\begin{array}{l}\text { Group } \\
(\mathrm{n}=25)\end{array}$ & P value & $\begin{array}{l}\text { Group } P \\
(n=25)\end{array}$ & $\begin{array}{l}\text { Group } \\
(n=25)\end{array}$ & C & P value \\
\hline Preoperative & $\begin{array}{l}143.8 \\
8.9\end{array}$ & \pm & $\begin{array}{l}138.1 \\
\pm 15.8\end{array}$ & & 0.126 & $75 \pm 9.5$ & $78.8 \pm 7.7$ & 0.123 & $99 \pm 8.1$ & $\begin{array}{l}100 \\
9.9\end{array}$ & \pm & 0.70 \\
\hline Induction & $\begin{array}{l}127.8 \\
5.8\end{array}$ & \pm & $\begin{array}{l}130.7 \\
13.4\end{array}$ & \pm & 0.337 & $68.4 \pm 10.8$ & $68.6 \pm 9.3$ & 0.933 & $89 \pm 7.7$ & $\begin{array}{l}91.5 \\
9.7\end{array}$ & \pm & 0.32 \\
\hline Intubation & $\begin{array}{l}105.8 \\
12.9\end{array}$ & \pm & $\begin{array}{l}112.6 \\
14.5\end{array}$ & \pm & 0.086 & $58.5 \pm 10$ & $58.6 \pm 8.6$ & 0.964 & $\begin{array}{l}73.4 \\
9.5\end{array}$ & $\begin{array}{l}77.9 \\
9.6\end{array}$ & \pm & 0.01 \\
\hline After 3 min & $\begin{array}{l}116.1 \\
12.4\end{array}$ & \pm & $123.2 \pm 1$ & 15 & 0.075 & $65.2 \pm 10.1$ & $64 \pm 9.6$ & 0.689 & $\begin{array}{l}83.8 \\
10.6\end{array}$ & $\begin{array}{l}84.5 \\
10.8\end{array}$ & \pm & 0.82 \\
\hline After 5 min & $\begin{array}{l}114.7 \\
10.1\end{array}$ & \pm & $\begin{array}{l}129 \\
16.2\end{array}$ & \pm & $<0.001^{*}$ & $60.4 \pm 6.5$ & $69.7 \pm 9.0$ & $<0.001 *$ & $\begin{array}{l}80.4 \\
7.9\end{array}$ & $\begin{array}{l}90.6 \\
9.9\end{array}$ & \pm & $<0.001 *$ \\
\hline After 10 min & $115 \pm 9.7$ & & $137.4 \pm 1$ & & $<0.001 *$ & $62.6 \pm 6.1$ & $\begin{array}{ll}73.8 & \pm \\
8.8 & \end{array}$ & $<0.001 *$ & $\begin{array}{l}82.1 \\
6.5\end{array}$ & $\begin{array}{l}96.9 \\
8.4\end{array}$ & \pm & $<0.001 *$ \\
\hline After 15 min & $\begin{array}{l}117.6 \\
6.4\end{array}$ & \pm & $\begin{array}{l}130.2 \\
14.8\end{array}$ & \pm & $<0.001 *$ & $67.1 \pm 8.8$ & $\begin{array}{l}70.6 \pm \\
11.7\end{array}$ & 0.239 & $\begin{array}{l}85.1 \\
6.4\end{array}$ & $\begin{array}{l}92.8 \\
12.3\end{array}$ & \pm & $0.008^{*}$ \\
\hline After 30 min & $\begin{array}{l}114.5 \\
9.9\end{array}$ & \pm & $129 \pm 14$ & 4.3 & $<0.001 *$ & $61.5 \pm 6.6$ & $\begin{array}{l}69.6 \pm \\
11.7\end{array}$ & 0.004 & $\begin{array}{l}81.4 \quad \pm \\
8.7\end{array}$ & $\begin{array}{l}91.2 \\
12.4\end{array}$ & \pm & $0.002^{*}$ \\
\hline After 45 min & $\begin{array}{l}115.8 \\
10.5\end{array}$ & \pm & $\begin{array}{l}133.9 \\
13.2\end{array}$ & \pm & $<0.001 *$ & $61.6 \pm 8.6$ & $\begin{array}{l}73.6 \pm \\
10.9\end{array}$ & $<0.001^{*}$ & $81.3 \pm 9$ & $\begin{array}{l}95.8 \\
12.3\end{array}$ & \pm & $<0.001 *$ \\
\hline After 60 min & $\begin{array}{l}113.4 \\
10.2\end{array}$ & \pm & $\begin{array}{l}130.8 \\
9.7\end{array}$ & \pm & $<0.001 *$ & $62.1 \pm 9.1$ & $74.5 \pm 8.7$ & $<0.001 *$ & $\begin{array}{l}80.4 \\
8.9\end{array}$ & $96 \pm 9$. & 3 & $<0.001 *$ \\
\hline After 75 min & $\begin{array}{l}114.5 \\
12.8\end{array}$ & \pm & $\begin{array}{l}133.1 \\
10.6\end{array}$ & \pm & $<0.001^{*}$ & $65.3 \pm 9.0$ & $77.9 \pm 8.1$ & $<0.001 *$ & $\begin{array}{l}82.3 \\
10.8\end{array}$ & $99 \pm 8$ & & $0.001 *$ \\
\hline After 90 min & $\begin{array}{l}114.6 \\
9.2\end{array}$ & \pm & $\begin{array}{l}132.2 \\
8.4\end{array}$ & \pm & $<0.001 *$ & $64.9 \pm 8.0$ & $72.9 \pm 7.1$ & $0.002^{*}$ & $84 \pm 7.3$ & $\begin{array}{l}95.1 \\
8.1\end{array}$ & \pm & $<0.001 *$ \\
\hline After $105 \mathrm{~min}$ & $\begin{array}{l}133.5 \\
27.6\end{array}$ & \pm & $\begin{array}{l}138.1 \pm \\
10.1\end{array}$ & & $<0.001^{*}$ & $67.8 \pm 1.7$ & $\begin{array}{l}72.8 \pm \\
10.3\end{array}$ & 0.216 & $\begin{array}{l}82.8 \\
8.3\end{array}$ & $\begin{array}{l}93.7 \\
10.7\end{array}$ & \pm & $0.006 *$ \\
\hline After $120 \mathrm{~min}$ & $\begin{array}{l}109.8 \\
12.9\end{array}$ & \pm & $\begin{array}{l}128.2 \\
6.7\end{array}$ & \pm & $<0.001 *$ & $66.2 \pm 12.6$ & $72.1 \pm 6.4$ & 0.119 & $\begin{array}{l}82.3 \\
12.5\end{array}$ & $93 \pm 6$ & & $0.01 *$ \\
\hline After $135 \mathrm{~min}$ & $\begin{array}{l}113.7 \\
15.7\end{array}$ & \pm & $135.5 \pm 9$ & & $0.004^{*}$ & $68 \pm 14.8$ & $74.3 \pm 3.7$ & 0.131 & $\begin{array}{l}84 \\
16.1\end{array}$ & $97.7 \pm$ & 6 & $<0.015^{*}$ \\
\hline After $150 \mathrm{~min}$ & $\begin{array}{l}133.5 \\
27.6\end{array}$ & \pm & $\begin{array}{l}138.1 \\
8.2\end{array}$ & \pm & 0.593 & $71 \pm 5.7$ & $73.9 \pm 7.7$ & 0.619 & $92 \pm 5.7$ & $\begin{array}{l}97.7 \\
8.2\end{array}$ & \pm & 0.367 \\
\hline $\begin{array}{l}3 \text { min after } \\
\text { extubation }\end{array}$ & $137 \pm 9.6$ & & $\begin{array}{l}151.8 \\
8.4\end{array}$ & \pm & $<0.001^{*}$ & $72.4 \pm 6.6$ & $\begin{array}{l}81.5 \\
11.4\end{array}$ & $0.001 *$ & $\begin{array}{l}97.2 \\
8.0\end{array}$ & $\begin{array}{l}105.8 \\
9.5\end{array}$ & \pm & $0.001 *$ \\
\hline $\begin{array}{l}10 \text { min after } \\
\text { extubation }\end{array}$ & $\begin{array}{l}125.8 \\
8.1\end{array}$ & \pm & $\begin{array}{l}143.6 \\
8.8\end{array}$ & \pm & $<0.001 *$ & $71.8 \pm 7.9$ & $81.8 \pm 7$ & $<0.001^{*}$ & $\begin{array}{l}95.7 \\
20.3\end{array}$ & $\begin{array}{l}105.6 \\
8.3\end{array}$ & \pm & $0.029 *$ \\
\hline
\end{tabular}

$* \mathrm{P}<0.05$ is considered statistically significant.

Table (4): Side effects and sedation in the pregabalin group (Group P) and control group (Group C).

Data are presented as number and percentage (\%). 


\begin{tabular}{|c|c|c|c|c|c|}
\hline & \multicolumn{2}{|c|}{$\begin{array}{c}\text { Pregabalin Group } \\
(\mathrm{n}=25)\end{array}$} & \multicolumn{2}{|c|}{$\begin{array}{c}\text { Control Group } \\
(n=25)\end{array}$} & \multirow[b]{2}{*}{$P$ value } \\
\hline & Number & $\%$ & Number & $\%$ & \\
\hline Nausea & 5 & $(20.0 \%)$ & 11 & $(44.0 \%)$ & 0.069 \\
\hline Vomiting & 2 & $(8.0 \%)$ & 5 & $(20.0 \%)$ & 0.417 \\
\hline Headache & 8 & $(32.0 \%)$ & 3 & $(12.0 \%)$ & 0.088 \\
\hline Dizziness & 15 & $(60.0 \%)$ & 2 & $(8.0 \%)$ & $<0.001 *$ \\
\hline Blurred vision & 6 & $(24.0 \%)$ & 1 & $(4.0 \%)$ & 0.098 \\
\hline \multicolumn{6}{|c|}{$1^{\text {st }}$ hour sedation score } \\
\hline 1 & 7 & $(28.0 \%)$ & 0 & $(0.0 \%)$ & $<0.001 *$ \\
\hline 2 & 10 & $(40.0 \%)$ & 0 & $(0.0 \%)$ & \\
\hline 3 & 7 & $(28.0 \%)$ & 3 & $(12.0 \%)$ & \\
\hline 4 & 1 & $(4.0 \%)$ & 14 & $(56.0 \%)$ & \\
\hline 5 & 0 & $(0.0 \%)$ & 8 & (32.0\%) & \\
\hline \multicolumn{6}{|c|}{$2^{\text {nd }}$ hour } \\
\hline 2 & 15 & $(60.0 \%)$ & 0 & $(0.0 \%)$ & $<0.001 *$ \\
\hline 3 & 7 & $(28.0 \%)$ & 1 & $(4.0 \%)$ & \\
\hline 4 & 3 & $(12.0 \%)$ & 24 & $(96.0 \%)$ & \\
\hline \multicolumn{6}{|c|}{$4^{\text {th }}$ hour } \\
\hline 2 & 1 & $(4.0 \%)$ & 0 & $(0.0 \%)$ & $<0.001^{*}$ \\
\hline 3 & 16 & (64.0\%) & 0 & $(0.00 \%)$ & \\
\hline 4 & 8 & (32.0\%) & 25 & (100.0\%) & \\
\hline \multicolumn{6}{|c|}{$6^{\text {th }}$ hour } \\
\hline 3 & 13 & (52.0\%) & 3 & (12.0\%) & $0.002 *$ \\
\hline 4 & 12 & (48.0\%) & 22 & (88.0\%) & \\
\hline
\end{tabular}

$\mathrm{P}^{*}>0.05$ is considered statistically significant.

\section{Figures}




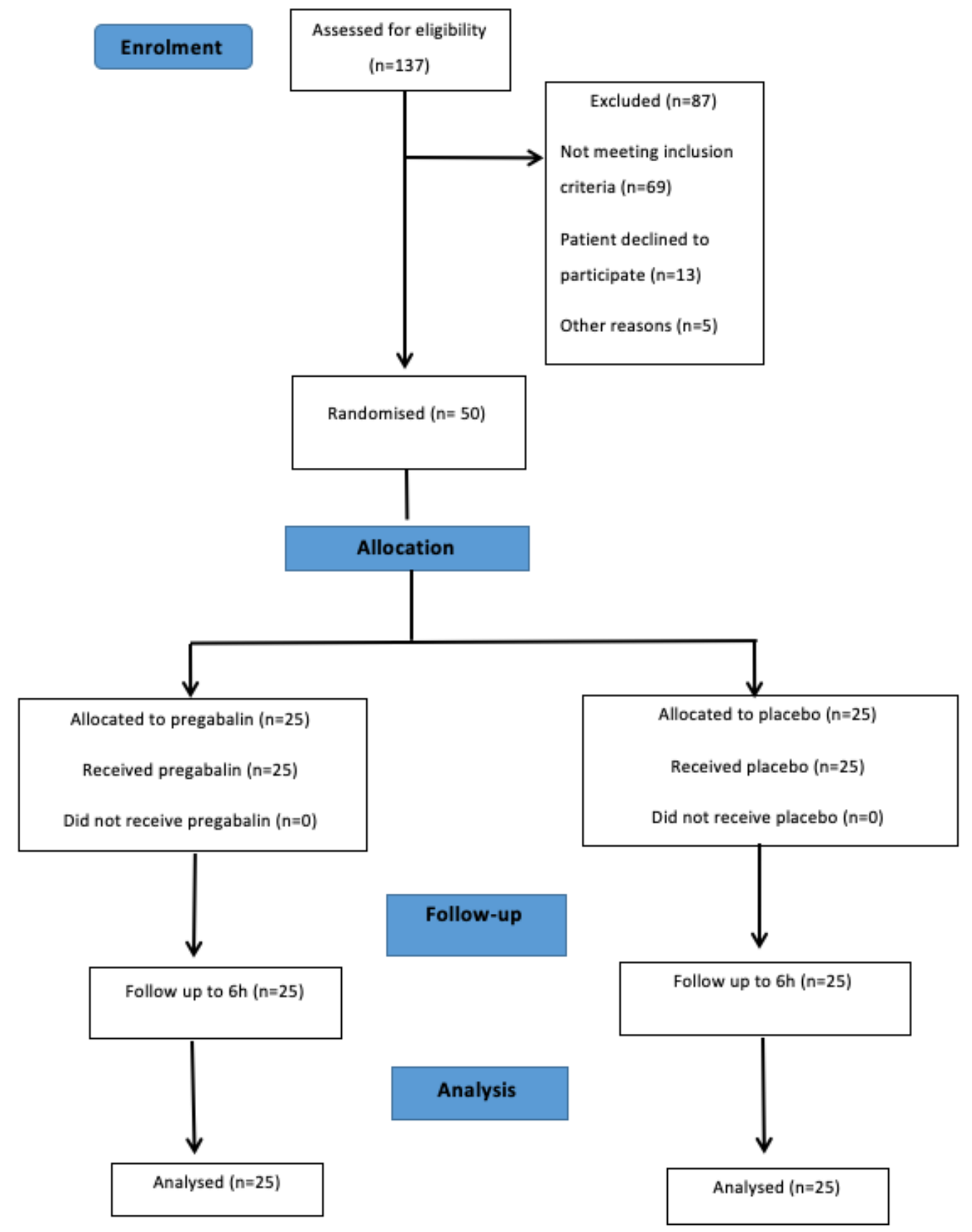

Figure 1

CONSORT diagram of the study. 

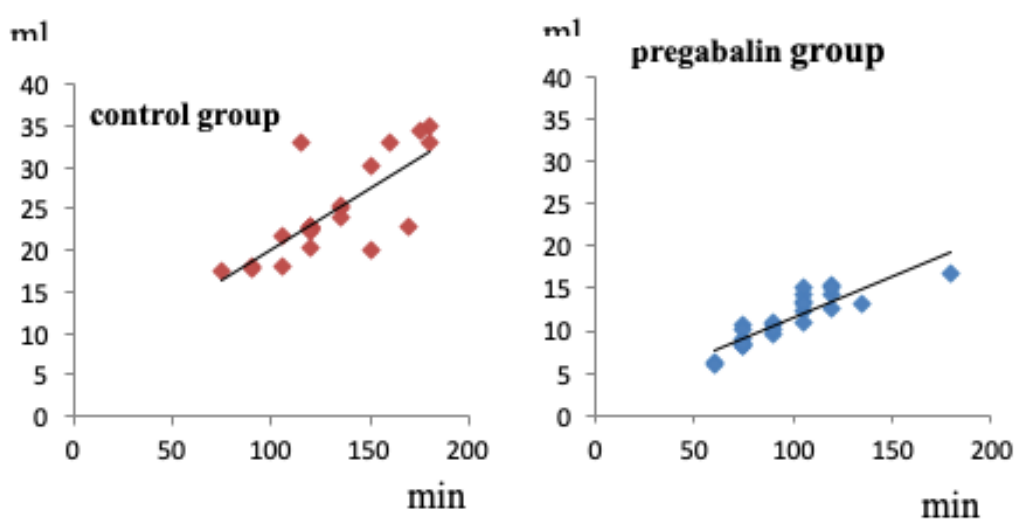

Figure 2: Total isoflurane consumption $(\mathrm{ml})$ throughout surgery $(\mathrm{min})$ by each patient in the control and pregabalin group.

\section{Figure 2}

Total isoflurane consumption $(\mathrm{ml})$ throughout surgery $(\mathrm{min})$ by each patient in the control and pregabalin group.

\section{Supplementary Files}

This is a list of supplementary files associated with this preprint. Click to download.

- supplement1.doc 